\title{
Two auditory aftereffects and their dependency on carrier frequency
}

\author{
A. H. REINHARDT-RUTLAND \\ Ulster Polytechnic, Newtownabbey, County Antrim BT37 OQB, Northern Ireland
}

\begin{abstract}
It is suggested that aftereffects caused by swept change of sound level (Reinhardt-Rutland \& Anstis, Note 1) may contribute to auditory motion aftereffects (Grantham \& Wightman, 1979). The latter appear to show selectivity for frequency; they are substantial if the frequency is $.5 \mathrm{kHz}$ but not if it is $2 \mathrm{kHz}$. An experiment was carried out to show to what extent there is such selectivity for aftereffects from swept sound-level change; this showed that they are substantial over a much wider range of frequencies than auditory motion aftereffects. It is concluded that the frequency selectivity of auditory motion aftereffects might be explained by frequency selectivity for interaural phase differences.
\end{abstract}

An aftereffect arising from perceived continuous movement of a tone has been recently reported (Grantham \& Wightman, 1979). The adapting stimulus consisted of repeated binaural presentation of a pair of tones with similar carrier frequency. Each pair of tones was varied in interaural sound level and phase difference during presentation so as to create a perception of continuous apparent movement of a single tone in one direction. After adaptation, an apparently steady tone stimulus appeared to move in the opposite direction. For example, decreasing sound level in the left ear and increasing sound level in the right ear, along with an increasing phase lead in the right ear, gave rise to perceived rightward movement of a tone; after adaptation, an apparently steady tone stimulus was perceived as moving leftward.

The effect was attributed to neurons sensitive to sound source movement (Altman, 1968; Altman, Syka, \& Shmigidina, 1970). However, an aftereffect of swept sound-level change in a tone (Reinhardt-Rutland \& Anstis, Note 1) may have contributed to the auditory motion aftereffect: Adaptation to slow swept decrease of a tone's sound level causes apparent increasing loudness in a steady tone. Conversely, adaptation to slow swept increase of a tone's sound level causes apparent decreasing loudness in a steady tone. Measurable aftereffects can arise from adapting stimuli with a rate of change of level as low as $\pm 3.75 \mathrm{~dB} \mathrm{sec}^{-1}$. Adaptation at one ear can give rise to an aftereffect at that ear, but there is little or no interaural transfer. This suggests that unilateral mechanisms are involved in the effects, and the authors were led to speculate that these mechanisms might be important in sound localization when it involves a moving sound source and/or observer (Reinhardt-Rutland \& Anstis, 1977). The degree of similarity between important aspects of the stimuli giving rise to these two different aftereffects suggests that they may have some mechanisms in common. However, Grantham and Wightman (1979) report that the auditory movement aftereffect occurs for tones of $.5 \mathrm{kHz}$ but not for tones of $2 \mathrm{kHz}$, whereas Reinhardt-Rutland and Anstis (Note 1) did not note such selectivity for frequency in their effect. The present report explores this point further by examining aftereffects of swept sound-level change at a wider range of frequencies than was examined in their earlier report.

\section{METHOD}

\section{Stimuli}

Stimuli were broadly similar to those used by Reinhardt-Rutland and Anstis (Note 1) and originated from the multiplication of the output of two function generators (Tektronix FG501 and Marconi 2021). The adaptation stimuli were tones whose sound level was saw-tooth modulated in one of two ways: Each modulation cycle consisted of either a slow swept increase of sound level followed by a fast fall in sound level, or a slow swept decrease of sound level followed by a fast rise of sound level (see Figure 1). Each fast rise or fall of level had a duration of $.2 \mathrm{msec}$ and was perceived as atonal. The mean sound level was $40 \mathrm{~dB}$ SPL and rate of change of level was $18 \mathrm{~dB} \mathrm{sec}$. Periodicity of modulation was $.5 \mathrm{~Hz}$. Half the adaptation stimuli had slow increase of level and half had slow decrease of level. Their carrier frequencies

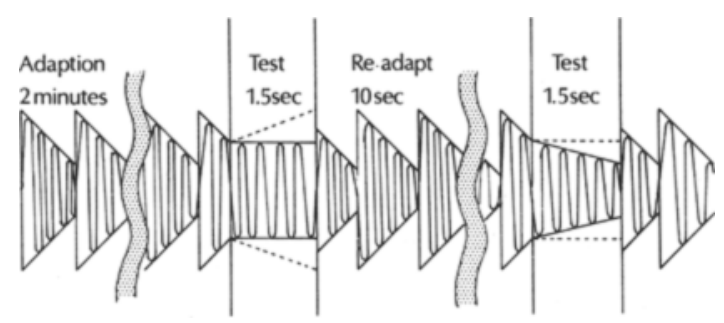

Figure 1. Schematic representation of decreasing sound-level adaptation and aftereffect. In the test tone on the left, the tone is steady in sound level but appears to be getting louder (represented by broken lines). In the test tone on the right, the aftereffect has been nulled and the tone appears to be steady. 
were: $.125, .25, .5,1.0,2.0$, and $4.0 \mathrm{kHz}$. Thus, there were 12 adaptation conditions in all.

The test stimuli, of $1.5 \mathrm{sec}$ duration, always started at a sound level of $40 \mathrm{~dB}$ and steadily increased or decreased, or remained constant in sound level. They had the same carrier frequencies as the adaptation stimuli with which they were coupled. For example, $.5-\mathrm{kHz}$ test stimuli were coupled with $.5-\mathrm{kHz}$ adaptation stimuli. Test and adaptation stimuli were diotically presented through Koss ESP6a electrostatic headphones in a sound-attenuating room.

\section{Subjects}

The subjects were three males, aged 22 to 28 , all of whom had had considerable prior practice with this type of task; one was the author. All had hearing sensitivity within normal limits as measured by a Kamplex model BA2C audiometer. All of the subjects were tested for adaptation to stimuli with a slow decrease in level, but only two were available for adaptation to stimuli with a slow increase in level.

\section{Procedure}

In any adaptation condition, the subject first adapted for $2 \mathrm{~min}$. He was then presented with a test tone followed by $10 \mathrm{sec}$ of readaptation, followed by another test tone, and so on. The subject made a forced binary response of "growing louder" or "growing softer" to each test stimulus.

During preliminary sessions for each adaptation condition, each subject responded to a wide range of test stimuli changing at a rate of between 8 and $-8 \mathrm{~dB} \mathrm{sec}-1$ in $1-\mathrm{dB} \mathrm{sec} \mathrm{steps}^{-1}$ (i.e., 17 test stimuli in all). The aftereffects were prominent within this range. From these, five stimuli were selected as being around the subject's null for the aftereffect (i.e., that value of test stimulus for which half the subject's responses were "growing louder" and half were "growing softer"). Over five experimental sessions, these stimuli were presented randomly 10 times each (50 test stimuli in all associated with each adaptation condition).

From each set of responses obtained in a given adaptation condition, a mean and standard deviation rate of change of level required to null the aftereffect was calculated using a method suggested by Engen (1971). The measured aftereffect was thus the negative of this value.

\section{RESULTS AND DISCUSSION}

Results shown in Figure 2 indicate that the aftereffects for both swept increase and decrease of sound level are substantial over the range of frequencies used. Notice a tendency for adaptation to decreasing sound level to produce larger effects than adaptation to increasing sound level. This may, however, be partly explained by a tendency to hear small decreases in sound level-but not small increases-as steady (Rawdon-Smith \& Grindley, 1935). Small (1977) also reported a tendency for steady or nearly steady tones to be heard as increasing in sound level. These findings could affect the perception of test stimuli in the present experiment and cause the subjects to make apparently small estimates of aftereffects from increasing soundlevel adaptation.

These aftereffects may arise from units selective for sound-level change (Gersuni \& Vartanyan, 1973; Nelson, Erulkar, \& Bryan, 1966). The lack of specificity for frequency in the present effects suggests that
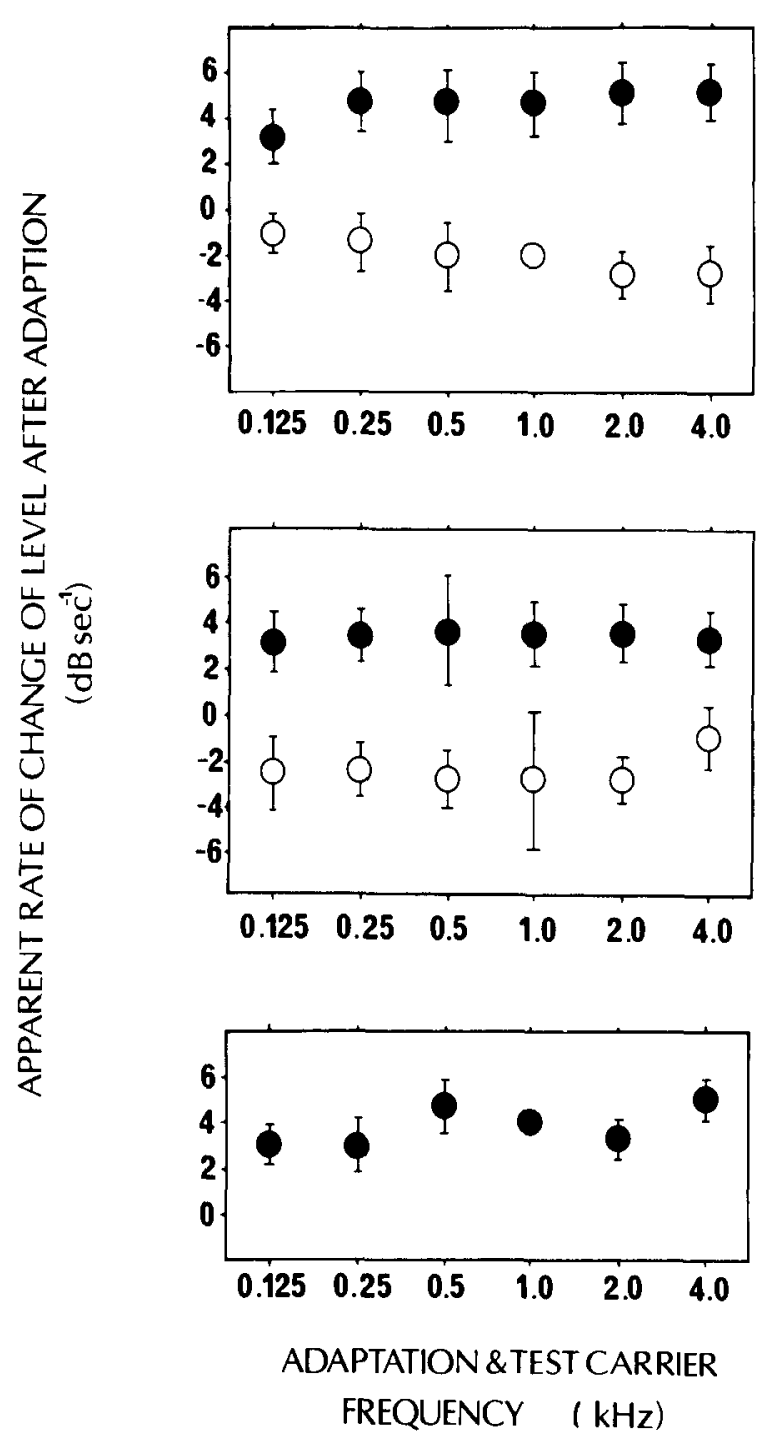

Figure 2. Aftereffects for three subjects: Filled circles are means for adaptation to swept decrease of sound level; open circles are for adaptation to swept increase of sound leve. Bars represent \pm SDs.

changing sound level may be analyzed at different sites to, and in parallel with, changing auditory movement. However, this overlooks aspects of comparability between the two effects: The apparent change of loudness resulting from adaptation to swept change of level might contribute to apparent movement of a tone in the auditory movement aftereffect. Another explanation might then be that changing sound level and changing auditory movement do share some sites of analysis; the frequency selectivity of auditory movement aftereffects would then be explained by frequency selectivity for interaural phase differences. The failure of interaural phase difference as a localization cue at higher frequencies (Mills, 1972; Sandel, Teas, Fedderson, \& Jeffress, 1955) supports this explanation. 


\section{REFERENCE NOTE}

1. Reinhardt-Rutland, A. H., \& Anstis, S. M. Auditory adaptation to gradual rise or fall in intensity of a tone (Report No. 50). Toronto, Canada: Department of Psychology, York University, 1976.

\section{REFERENCES}

Altman, J. A. Are there neurons detecting direction of sound source movement? Experimental Neurology, 1968, 22, 13-25.

Altman, J. A., Syka, J., \& Shmigidina, G. N. Neuronal activity in the medial geniculate body of the cat during monaural and binaural stimulation. Experimental Brain Research, 1970, 10, $81-93$.

Engen, T. Psychophysics 1. Discrimination and detection. In J. W. Kling \& L. A. Riggs (Eds.), Woodworth and Schlosberg's experimental psychology. New York: Holt, Rinehart \& Winston, 1971.

Gersuni, G. V., \& Vartanyan, I. A. Time dependent features of adequate sound stimuli and the functional organization of central auditory neurons. In A. R. Mфller (Ed.), Basic mechanisms in hearing. New York: Academic Press, 1973.

Grantham, D. W., \& Wightman, F. L. Auditory motion aftereffects. Perception \& Psychophysics, 1979, 26, 403-408.
Mills, A. W. Auditory localization. In J. V. Tobias (Ed.), Foundations of modern auditory theory II. New York: Academic Press, 1972

Nelson, P. G., Erulkar, S. D., \& Bryan, J. S. Responses of units of the inferior colliculus to time-varying acoustic stimuli. Journal of Neurophysiology, 1966, 29, 834-860.

Rawdon-Smith, A. F., \& Grindley, G. C. An illusion in the perception of loudness. British Journal of Psychology, 1935, 26, 191-195.

Reinhardt-Rutland, A. H., \& Anstis, S. M. Adaptation effects arising from swept amplitude change of tones (Second Easter Meeting, Brain Research Association, University of Bath, England, 1977). Brain Research Association Bulletin No. 25, 1977. (Abstract)

Sandel, T. T., Teas, D. C., Fedderson, W. E., \& Jefrress, L. A. Localization of sound from single and paired sources. Journal of the Acoustical Society of America, 1955, 27, 842-852.

SMALl, A. M. Loudness perception of signals of monotonically changing sound pressure. Journal of the Acoustical Society of America, 1977, 61, 1293-1297.

(Received for publication May 19, 1980; revision accepted September 5, 1980.) 